\title{
Anaplastic Large Cell Lymphoma Mimicking a Necrotizing Granulomatous Lesion: A Case Report
}

\section{Tralongo V, Becchina G, Nagar C, Ottoveggio G, Giacalone B, Canciglia R and Genovese F*}

Department of Diagnostic Laboratory, Laboratory of Pathologic Anatomy, "G.F. Ingrassia” Hospital, Azienda Sanitaria Provinciale Di Palermo, Italy

*Corresponding author: Francesco Genovese, Department of Diagnostic Laboratory, Laboratory of Pathologic Anatomy, “G.F. Ingrassia” Hospital, Azienda Sanitaria Provinciale Di Palermo, Italy, Tel: +39 +91 7033441; E-mail: francescogenovese@asppalermo.org

\section{Abstract}

Introduction: Epithelioid cell granulomas into neoplastic tissues have been reported in association with a wide series of neoplasms, including lymphomas. Epithelioid granulomas in association with non-Hodgkin's lymphomas are only rarely observed. When granulomas are present in association with lymphomas, they are usually non necrotizing, sarcoid-like. Little is known about the association of granulomatous reaction with anaplastic large cell lymphoma (ALCL) and to the best of our knowledge anaplastic large-cell lymphoma with histological features of necrotizing granulomatous lesion has not been reported previously in the literature. In this article we report a case of anaplastic large-cell lymphoma mimicking a necrotizing granulomatous lymphadenitis.

Case Presentation Section: A 55-year-old Caucasian man presented with a 3-month history of a painless, enlarged, lymph node localized on the left inguinal region. Escissional biopsy was performed. The microscopic examination led to the diagnosis of granulomatous lymphadenitis with necrosis.

Two months later the patient returned because he had note the appearance of a nodule in the right axillary region. Following the escissional biopsy, the histological examination and the immunohistochemical stains have been made the diagnosis of ALCL, ALK1 negative. The first case was revaluated. Extensive immunophenotypic characterization (positivity for CD45RO/UCHL1 and CD-30 in the areas of necrosis), in conjunction with histomorphologic and molecular analysis (presence of a T monoclonal cell lymphoid), established diagnosis of ALCL ALK-1 negative.

Conclusions: The presence of exaggerated granulomatous reaction in tissue involved by lymphomas may mask neoplastic lymphoid cells and result in erroneous histopathologic diagnosis.

In this article we report a case of primary nodal ALCL mimicking a necrotizing granulomatous lymphadenitis.

Keywords: Anaplastic large cell lymphoma; Epithelioid cell granulomas; Misdiagnosis; Immunohistochemical; Hepatosplenomegaly 


\section{Medical Journal of Clinical Trials \& Case Studies}

Abbreviations: ALCL: Anaplastic Large Cell Lymphoma

\section{Introduction}

Epithelioid cell granulomas into neoplastic tissues have been reported in association with a wide series of neoplasms, including lymphomas. Between lymphomas, Hodgkin's lymphoma and T-cell derived non Hodgkin lymphoma are more seen commonly [1]. The presence of non-necrotic epithelioid cell granulomas is well known findings in lymph nodes, spleen, bone marrow, and liver from patients with Hodgkin's disease [2-4]. Epithelioid granulomas in association with non-Hodgkin's lymphomas are only rarely observed $[5,6]$.

When granulomas are present in association with lymphomas, they are usually non necrotizing, sarcoid-like [7-9]. Nevertheless, rarely necrotizing granulomas occurs.

Hall et al. reported two cases of high-grade malignant lymphoma characterized by extensive necrosis in association with granulomatous reaction mimicking tuberculosis $[10,11]$.

Chow et al. reported three cases of lymphomas masquerading as granulomatous panniculitis from inflammatory or reactive disorders associated [12].

In these cases an infectious cause is not found and their development has been attributed to an immune or inflammatory reaction to tumour-associated antigens, probably [13-15].

Little is known about the association of granulomatous reaction with anaplastic large cell lymphoma and to the best of our knowledge anaplastic large-cell lymphoma with histological features of necrotizing granulomatous lesion has not been reported previously in the literature. In this article we report a case of anaplastic large-cell lymphoma mimicking a necrotizing granulomatous lymphadenitis.

\section{Case Presentation Section}

Case Report: a 55-year-old Caucasian man in otherwise good health, presented with a 3-month history of a painless, enlarged, lymph node localized on the left inguinal region. The man had no fever, weight loss or night sweats. Physical examination revealed no other lymph node involvement. There was no hepatosplenomegaly. The chest x-ray was unremarkable. Blood-cell count, serum biochemistry and immunoglobulins, Mantoux test and Epstein-Barr virus antibody titer were either within normal limits or negative. Escissional biopsy was performed. The lymph node was $2 \mathrm{~cm}$ in diameter and on cut surface it showed multiple, round formations, yellow in colour.

At microscopic examination there was complete effacement of nodal structure with multiple granulomas with central necrosis (Figure 1a \& 1b). Ziehl-Neelsen satin for acid fast bacilli was negative as well as the fungal stains (periodic acid-Schiff and Grocottmethenamine silver). A diagnosis of granulomatouslymphadenitis with necrosis was performed.

Two months later the patient returned because he had note the appearance of a nodule in the right axillary region, which was rapidly increasing in size. Escissional biopsy was performed. At histological examination the normal lymph node architecture was totally effaced by a diffused growth consisting of large, highly pleomorphic lymphoid cells. Immunohistochemical stains demonstrated that the neoplastic cells were positive for CD45RB/LCA (clone 2B11+PD7/26, Roche-Ventana), CD45RO (clone UCHL1, Roche-Ventana), CD30 (clone BerH2, Roche-Ventana), focally CD-3 (clone 2GV6, RocheVentana), while were negative for CD20 (clone L26, Roche-Ventana) and ALK-1 protein (clone ALK01, RocheVentana). Approximately $80 \%$ of the neoplastic cells reacted positively when stained with an antibody to Ki-67 (clone 30-9, Roche-Ventana). $\mathrm{T}$ cell receptor rearrangement was found. A diagnosis of anaplastic largecell lymphoma ALK1 negative was performed.

The first case was revaluated and immunohistochemical and molecular studies were performed. Immunohistochemical analysis demonstrated positivity for CD45RO, CD-30 in the areas of necrosis (Figure 1c \& 1d) and CD3 focally (Figure 1e \& 1f). To confirm the neoplastic feature of this cell population, the presence of rearrangement of TCR gene was investigated. 


\section{Medical Journal of Clinical Trials \& Case Studies}

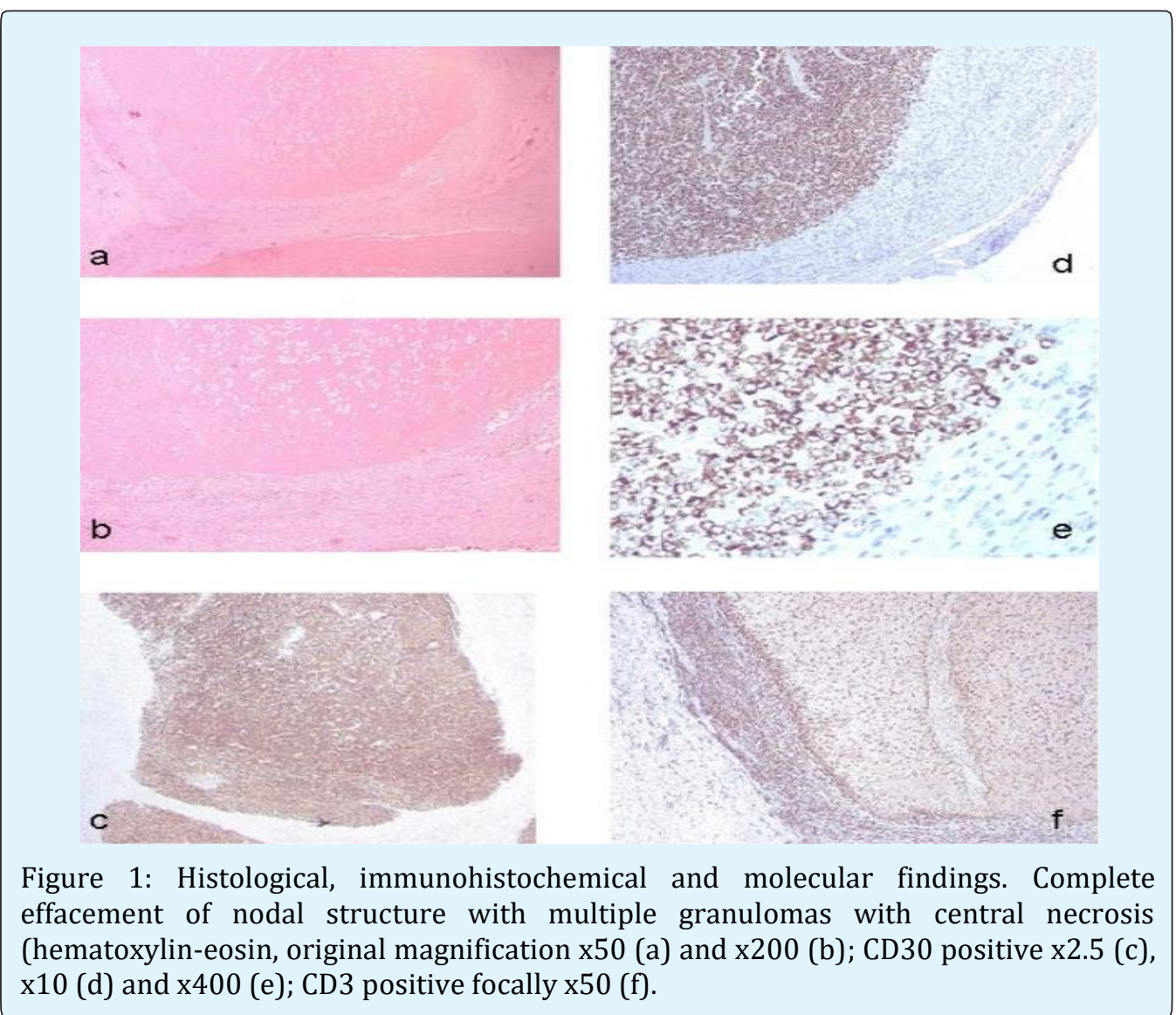

$\mathrm{T}$ clonality molecular study showed a monoclonal configuration of the TCRG and TCRB genes (Figure 2).

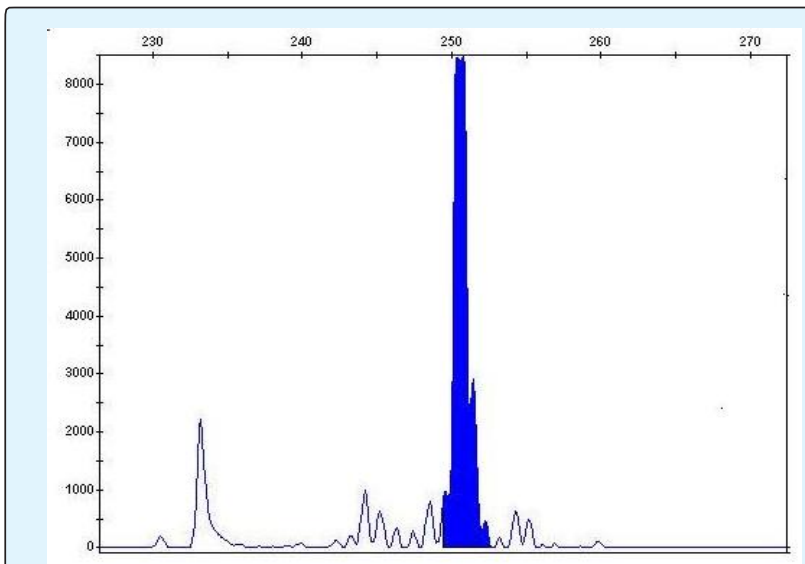

Figure 2: Clonality assessment. GeneScan results of the gene rearrangement profile in the sample patient, showing the peak clonal TCRG rearrangement with multiple primer sets in a polyclonal background. Gene rearrangement of TCRB and polyclonal tonsil biopsy FFPE control are not shown.
The T-cell clonality assay employs primers for both TCRB and TCRG, a combination that has been shown to detect clonality in essentially $100 \%$ of T-cell prolymphocytic leukemias, T-cell large granular lymphocyte disorders, and peripheral T-cell lymphomas, unspecified, with somewhat lower rates reported in angioimmunoblastic T-cell lymphomas and anaplastic large cell lymphoma $[16,17]$.

Commercial reagents by ROCHE VENTANA, Italy were used to perform immuno-hystochemical assay and by EXPERTEAM (Marghera Venezia, Italy) and INVIVOSCRIBE TECHNOLOGIES (San Diego, California USA) were used to perform beta-globin and clonality $\mathrm{T}$ assay, respectively. All used products are compliant to the requirements of the in vitro diagnostic directive (IVDD) 98/79/EC.

\section{Discussion}

The majority of cancer diagnoses are made on the basis of either histologic or cytologic evaluation. Generally, the error frequency and effect are poorly characterized 


\section{Medical Journal of Clinical Trials \& Case Studies}

because there is no uniform measurement process, but, in this case, the current guide lines and the appropriated procedures have been respected.

Here, we report a case of primary nodal anaplastic large-cell lymphoma mimicking a necrotizing granulomatous lymphadenitis. Rarely, the diagnosis of a lymphoma may be masked by the presence of extensive granulomatous lesions. Lymphomas associated with marked granulomatous reaction are well documented in the literature [8].

Malignant lymphomas and solid tumours that mimic or are associated with epithelioid granulomas are a dilemma in histological materials. Granulomatous lymphadenitis may be determined by several infective agents or determined by different pathological processes, sarcoidosis and tuberculosis being the most frequent. Granulomatous lymphadenitis may also occur along haematological diseases or after chemotherapy or radiotherapy. Granulomatous reaction after chemotherapy for Hodgkin's disease has been described in the literature [14]. A prognostic relevance of the granulomatous reaction in ALCL lymphoma is not clear. Little is known about the association of granulomatous reaction with anaplastic large cell lymphoma (ALCL) [18].

The differential diagnosis of necrotizing granulomas includes chronic infections such as typical and atypical mycobacterium, fungi (e.g., histoplasmosis, aspergillosis, cryptococcosis), and Wegener's granulomatosis, as well as foreign body type granulomatous inflammations [18].

In our case an infectious cause is not found and granuloma development could be attribute to an immune or inflammatory reaction to tumor-associated antigens $[1,13]$.

This case emphasizes the importance of a very careful microscopic evaluation of the lymph nodes with nonnecrotizing granuloma searching for any large atypical cells that may represent hidden malignant cells that can be easily overlooked.

In addition, the massive necrosis found here, could call in question the veracity of the immunohistochemical and molecular assays.

Many authors reported cases of lymphomas with complete lymph node necrosis in which immunophenotypic and immunogenotypic studies were performed successfully $[19,20]$.

After the diagnosis, the patient underwent to oncology visit in a different hospital, so it was not possible to know the stage of lymphoma or the appropriated therapeutic treatment. Although, it should be very interesting, here we want principally to focus attention on the histological diagnosis.

We describe a case of an unusual ALCL lymphoma that was associated with exuberant granulomatous reaction and has been misdiagnosed as necrotizing granulomatous lymphadenitis.

\section{Conclusion}

The purpose of this article is to provide a strong suggestion for pathologists. In fact, the aim of this case report is to emphasize the importance of an extensive immunophenotypic characterization, in conjunction with histomorphologic and molecular analysis in all instances of the lymph nodes with granulomatous reaction. This case highlights the importance of a careful assessment of any necrosis in lymph node, using a multimodality diagnostic approach to distinguish lymphomas masquerading as granulomatous lesion from inflammatory or reactive disorders associated with such histopathologic patterns, specially, when the diagnosis should be wrong and the treatment cannot be delayed and/or imprecise.

\section{References}

1. Basu D, Bundele M (2005) Angioimmunoblastic T-cell lymphoma obscured by concomitant florid epithelioid cell granulomatous reaction: a case report. Indian J Pathol Microbiol 48(4): 500-502.

2. Kadin ME, Donaldson SS, Dorfman RF (1970) Isolated granulomas in Hodgkin's disease. N Engl J Med 283(16): 859- 861.

3. Bricken H (1972) Sarcoid reactions and sarcoidosis ion Hodgkin's disease and other malignant lymphomata. Br J Cancer 26: 120-128.

4. Juan B Laforga, F Ignacio Aranda, Joan M Gasent (2009) Splenic marginal B-cell lymphoma with epithelioid granulomas. Report of a case with cytologic and immunohistochemical study. Cancer Therapy 7(1): 21-26. 


\section{Medical Journal of Clinical Trials \& Case Studies}

5. Dorfman RF, Kim H (1975) Relationship of histology to site in the non-Hodgkin's lymphomta: A study based on surgical staging procedures. $\mathrm{Br} \mathrm{J}$ Cancer Suppl 2: 217-220.

6. Hall PA, Kingston J, Stansfeld AG (1988) Extensive necrosis in malignant lymphoma with granulomatous reaction mimicking tuberculosis. Histopathology 13(3): 339-346.

7. Hollingsworth HC, Longo DL, Jaffe ES (1993) Small noncleaved cell lymphoma associated with florid epithelioid granulomatous response. A clinicopathologic study of seven patients. Am J Surg Pathol 17(1): 51-59.

8. Braylan RC, Long JC, Jaffe ES, Greco FA, Orr SL, et al. (1977) Malignant lymphoma obscured by concomitant extensive epithelioid granulomas: report of three cases with similar clinicopathologic features. Cancer 39(3): 1146-1155.

9. Haralambieva E, Rosati S, van Noesel C, Boers E, van Marwijk Kooy M, Schuuring E, Kluin P (2004) Florid granulomatous reaction in Epstein-Barr viruspositive nonendemic Burkitt lymphomas: Report of four cases. Am J Surg Pathol 28(3): 379-383.

10. Dunphy CH, Panella MJ, Grosso LE (2000) Low-grade B-cell lymphoma and concomitant extensive sarcoidlike granulomas: a case report and review of the literature. Arch Pathol Lab Med 124 (1): 152-156.

11. Strickland Marmol LB, Fessler RG, Rojiani AM (2000) Necrotizing sarcoid granulomatosis mimicking an intracranial neoplasm: clinicopathologic features and review of the literature. Mod Pathol 13(8): 909-913.

12. Cherie H Dunphy, Michael J Panella, Leonard E Grosso (2000) Low-Grade B-cell lymphoma and concomitant extensive sarcoidlike granulomas. Arch Pathol Lab Med 24: 152-156.

13. Balamurugan S, Rajasekar R, Ramesh Rao R (2009) Anaplastic large-cell lymphoma with florid granulomatous reaction: a case report and rewiev of literature. Indian J Pathol Microbiol 52(1): 69-70.

14. Al Maghrabi JA, Sawan AS, Kanaan HD (2006) Hodgkin's lymphoma with exuberant granulomatous reaction. Saudi Med J 27(12): 1905-1907.

15. Chow KF, Ritchie E, Husain S, Alobeid B, Bhagat G (2011) Lethal T- and NK-cell lymphomas mimicking granulomatous panniculitidies: a clinicopathologic study of three cases. J Cutan Pathology 38(6): 483491.

16. Nikiforova MN, His ED, Braziel RM, Gulley ML, Leonard DG, et al. (2007) Detection of clonal IGH gene rearrangements: summary of molecular oncology surveys of the College of American Pathologists. Arch Pathol Lab Med 131(2): 185-189.

17. Van Dongen JJ, Langerak AW, Brüggemann M, Evans PA, Hummel $M$, et al. (2003) Design and standardization ofPCR primers and protocols for detection of clonal immunoglobulin and T-cell receptor gene recombinations in suspect lymphoproliferations: report of theBIOMED-2 Concerted Action BMH4-CT98-3936. Leukemia 17(12): 2257-2317.

18. Strauchen JA,Miller LK (2003) Lymph node infarction. An immunohistochemical study of 11 cases. Arch Pathol Lab Med 127(1): 60-63.

19. Norton AJ, Ramsay AD, Isaacson PG (1988) Antigen preservation in infarcted lymphoid tissue. A novel approach to the infarcted lymph node using monoclonal antibodies effective in routinely processed tissues. Am J Surg Pathol 12(10): 759-767.

20. Vega F, Lozano MD, Alcade J, Pardo Mindan FJ (1999) Utility of immunophenotypic and immunogenotypic analisys in the study of necrotic lymph nodes. Virchows Arch 434: 245-248. 